\title{
AVALIAÇÃO DA LEITURA E ESCRITA NO CONTEXTO DA ALFABETIZAÇÃO: UM ESTUDO DAS PESQUISAS NACIONAIS ${ }^{1}$
}

\author{
READING AND WRITING ASSESSMENT IN THE CONTEXT OF LITERACY: \\ A STUDY OF NATIONAL RESEARCH
}

\section{EVALUACIÓN DE LA LECTURA Y LA ESCRITURA EN EL CONTEXTO DE LA ALFABETIZACIÓN: UN ESTUDIO DE LA INVESTIGACIÓN NACIONAL}

\author{
Aline Gasparini Zacharias-Carolino ${ }^{2}$ \\ Andréia Osti ${ }^{3}$
}

\begin{abstract}
Resumo: Este trabalho objetiva compreender, por intermédio de uma revisão sistemática da literatura, as formas de avaliação da leitura e da escrita no contexto da alfabetização. Os resultados indicam uma dicotomia entre os instrumentos e as formas de avalição presentes nos artigos analisados.

Palavras-chave: Avaliação da aprendizagem; ensino fundamental; ciclo básico de alfabetização.
\end{abstract}

\begin{abstract}
This work aims to understand, through a systematic literature review, the forms of evaluation of reading and writing in the context of literacy. The results indicate a dichotomy between the instruments and the forms of assessment present in the articles.
\end{abstract}

Keywords: Learning assessment; elementary school; basic literacy cycle.

Resumen: Este trabajo tiene como objetivo comprender, a través de una revisión sistemática de la literatura, las formas de evaluación de la lectura y la escritura en el contexto de la alfabetización. Los resultados indican una dicotomía entre los instrumentos y las formas de evaluación presentes en los artículos analizados.

Palabras clave: Evaluación del aprendizaje; escuela primaria; ciclo básico de alfabetización.

\section{Introdução}

A aprendizagem inicial da leitura e da escrita constitui-se como um processo multifacetado e, portanto, complexo, que apresenta uma pluralidade de abordagens e formas de compreensão e, ao mesmo tempo, se insere em um cenário de dissonâncias, crises, contradições, pluralidades e possibilidades. Nesse sentido, a temática é amplamente discutida tanto no âmbito acadêmico, como nas escolas de educação básica, diante da relevância que a leitura e a escrita desempenham em uma sociedade que se organiza em torno da língua escrita (SOARES, 2018).

Tais discussões abordam desde práticas didático-pedagógicas, formação de professores alfabetizadores, avaliação interna e externa, materiais didáticos, dentre outros. Especialmente, as avaliações da alfabetização assumem grandes proporções, na medida em que os resultados de avaliações externas são amplamente difundidos, sendo muitas vezes utilizados como parâmetros para o desenvolvimento do trabalho em sala de aula (MORAIS, 2012). Assim, pressupõe-se que as formas de avaliação nas salas de alfabetização influenciam diretamente o processo de ensino-aprendizagem, incidindo não só na maneira como o aluno se vê no ambiente

\footnotetext{
${ }^{1}$ A presente pesquisa foi realizada com o apoio da Fundação de Amparo à Pesquisa do Estado de São Paulo (FAPESP).

${ }^{2}$ Universidade Estadual Paulista - UNESP.

${ }^{3}$ Universidade Estadual Paulista - UNESP.
} 
escolar, mas funcionando como um fator preditivo da exclusão intraescolar e, ainda, como um fator que também influencia, em maior ou menor medida, no planejamento docente.

De acordo com Perrenoud (1999), as discussões acerca da avaliação avançaram muito, contudo ainda trazem indícios das avalições meramente mensuradoras e coercitivas. Assim, o autor destaca que "[...] a avaliação jamais é pensada em si mesma, mas como componente de um sistema de ação" (PERRENOUD, 1999, p. 18, grifos originais). Por conseguinte, a avaliação sempre está associada a uma tomada de decisão, estando diretamente relacionada à ação pedagógica.

Nessa perspectiva, emerge a necessidade de um olhar atento para com essa temática indissociável do trabalho docente, ao se levar em consideração que a avaliação é uma forma de reflexão sobre o processo de ensino-aprendizagem e, consequentemente, sobre o próprio trabalho didático-pedagógico. Diante do exposto, este artigo refere-se a um recorte de uma pesquisa de doutorado, financiada pela Fundação de Amparo à Pesquisa do Estado de São Paulo (FAPESP), e objetiva compreender, por intermédio de uma revisão sistemática da literatura nacional, as formas de avaliação da leitura e da escrita, assim como quais instrumentos são utilizados no contexto da alfabetização, considerando que diferentes modelos de avaliação, inerentemente, trazem em sua essência concepções de alfabetização e de educação. Para tanto, foi realizado um levantamento bibliográfico nas bases de dados do Scientific Electronic Library Online (SciELO) e dos Periódicos da Coordenação de Aperfeiçoamento de Pessoal de Nível Superior (CAPES), abrangendo o período condizente com os últimos dez anos.

Desse modo, o trabalho está organizado em quatro seções. A primeira seção trará uma discussão conceitual acerca da avaliação da leitura e da escrita nos anos iniciais do Ensino Fundamental. Na segunda seção, será apresentada a metodologia, assim como o processo de seleção dos textos e as categorias de análise. Na terceira seção, serão apresentados os resultados, enfatizando aspectos quanti e qualitativos, que ilustram o panorama atual das pesquisas encontradas, por meio da revisão realizada. Por fim, haverá as considerações finais a respeito dos dados analisados.

\section{A avaliação da alfabetização nos anos iniciais do ensino fundamental}

De acordo com Carminatti e Borges (2012), a problemática que envolve a avaliação da aprendizagem manifesta distintas configurações no decorrer do tempo. Tal pressuposto pode ser também pensado no contexto dos anos iniciais do ensino fundamental, uma vez que diferentes formas de compreender o processo de alfabetização reverberam em maneiras de interpretar a avaliação da leitura e da escrita no âmbito da sala de aula.

Morais e Leal (2020), ao realizarem um exame retrospectivo, ponderam que a avaliação da alfabetização, atualmente, ainda se constitui como um tema pouco explorado em pesquisas nacionais. Aliado a isso, destacam que muitos professores apresentam dificuldades para diagnosticar os conhecimentos de seus estudantes no decurso do ciclo de alfabetização. Assim, serão apresentados, brevemente, alguns estudos que trazem para a discussão aspectos relacionados à avaliação da alfabetização no contexto da sala de aula e que, portanto, estão diretamente articulados ao planejamento do trabalho docente e às práticas pedagógicas.

Sperrhake e Piccoli (2020) realizaram uma análise qualitativa de instrumentos de avaliação utilizados no trabalho com turmas de $1^{\circ}$ ano do ensino fundamental de escolas de redes públicas de ensino estadual do Rio Grande do Sul e do município de Porto Alegre, no período referente aos anos de 2015 a 2019. Nesse contexto, as autoras evidenciaram que as professoras fizeram uso de vários instrumentos avaliativos, dentre eles podem ser mencionados os jogos e as folhas estruturadas, que foram produzidas pelas próprias professoras, com propostas de escrita de palavras e frases a partir de imagens, leitura de palavras, leitura de frases e associação com desenhos, dentre outras possibilidades. 
Para além disso, as docentes faziam uso do conhecido "teste psicogenético de escrita", que se embasa nos pressupostos de Ferreiro e Teberosky (1999) e que consiste na escrita de palavras com diferentes constituições silábicas pertencentes a um mesmo campo semântico e na escrita de uma frase. Contudo, um aspecto interessante a se destacar é que as autoras constataram também a existência de outras formas de interpretação das escritas infantis, como a baseada no paradigma fonológico, que é amplamente dissecado por Soares (2018).

Por conseguinte, Sperrhake e Piccoli (2020) enfatizam a importância da seleção das palavras que compõem os instrumentos construídos e da necessidade de se levar em conta os aspectos linguísticos que estão diretamente articulados ao trabalho desenvolvido em sala de aula, assim como a diversificação dos instrumentos utilizados, dado que isso se torna um contributo ao planejamento das professoras e ao avanço do processo de aprendizagem dos alfabetizandos, haja vista que dimensionam que "[...] levando em conta esses princípios, entendemos que o olhar interpretativo da professora, com base nas diferentes teorias que explicam o processo de aprendizagem inicial da leitura e da escrita, é que vai direcionar a avaliação das aprendizagens dos alunos" (SPERRHAKE; PICCOLI, 2020, p. 65).

As práticas avaliativas de professoras alfabetizadoras atuantes em turmas do $1^{\circ}$ do ensino fundamental foram também investigadas por Lima (2015), em sua pesquisa de mestrado, por meio da qual a autora buscou compreender como era o processo avaliativo ao longo do ano letivo, como ocorria essa avaliação e de que forma os resultados influenciavam nas práticas em sala de aula no contexto da aprendizagem inicial da leitura e da escrita. Os resultados indicaram que as docentes participantes da pesquisa utilizavam diferentes instrumentos avaliativos no decorrer do ano letivo, dentre eles podem ser mencionados a sondagem, o teste elaborado pelas docentes com base na Provinha Brasil, fichas de lições, dentre outros e, ainda, outro aspecto que se destacou foi o registro dos resultados em suportes variados, tais como as tabelas, as planilhas e as narrativas, o que favorecia a consulta das professoras aos materiais.

Não obstante, Lima (2015) preconiza que a utilização de instrumentos variados pode favorecer o desenvolvimento do trabalho do professor e auxiliá-lo na compreensão das necessidades dos alunos, algo que vai ao encontro da pesquisa de Sperrhake e Piccoli (2020), contudo menciona também que essa diversificação de instrumentos deve estar articulada ao planejamento de atividades e de práticas pedagógicas contextualizadas. Outrossim, partindo da ponderação de que a avaliação da alfabetização ainda é um tema pouco explorado, da dificuldade inerente que permeia as discussões sobre a temática e da diversidade de instrumentos e práticas, assim como formas de interpretação desses instrumentos existentes nas escolas de educação básica, é que surgiu a proposição deste estudo, que, como já mencionado, se refere ao recorte de uma pesquisa de doutorado em fase de desenvolvimento.

\section{Metodologia}

Este estudo se caracteriza como descritivo e procedeu a uma revisão sistemática de literatura, com ênfase na seleção de artigos nas bases de dados do Scientific Electronic Library Online (SciELO) e Periódicos da Coordenação de Aperfeiçoamento de Pessoal de Nível Superior (CAPES), abrangendo o período temporal dos últimos dez anos (2010 - 2020) e com a utilização dos descritores "avaliação" and "alfabetização", "avaliação" and "escrita", "avaliação" and "leitura.

Dada essas características, optou-se pela realização de uma revisão da literatura que envolve a leitura e a escrita de forma conjunta, por considerarmos que, nesta fase da pesquisa, seria pertinente termos uma dimensão de como a temática vem sendo discutida ao ser direcionada ao campo da alfabetização, buscando até mesmo realizar identificações iniciais sobre possíveis lacunas em relação aos construtos e como eles se entrelaçam (ou não) nas investigações. 
Nesse contexto, foram encontrados 395 artigos. Para tanto, houve a leitura dos resumos e o estabelecimento de alguns critérios para seleção, a saber: a) ser redigido em língua portuguesa; b) ser direcionado ao público pertencente aos anos iniciais do ensino fundamental. Ao final, após exclusão das duplicatas, permaneceram 28 artigos que se aproximavam dos objetivos desta pesquisa. Sendo assim, houve o estabelecimento de sete categorias de análise: ano de publicação, tipos de pesquisa, participantes, construto abordado (leitura, escrita, leitura \& escrita), áreas do conhecimento, instrumentos e temáticas.

\section{Resultados e discussão}

A primeira categoria analisada foi o ano de publicação dos trabalhos que fizeram parte do espoco de análise. O gráfico abaixo corresponde à distribuição dos artigos de acordo com o período delimitado, isto é, de 2010 a 2020.

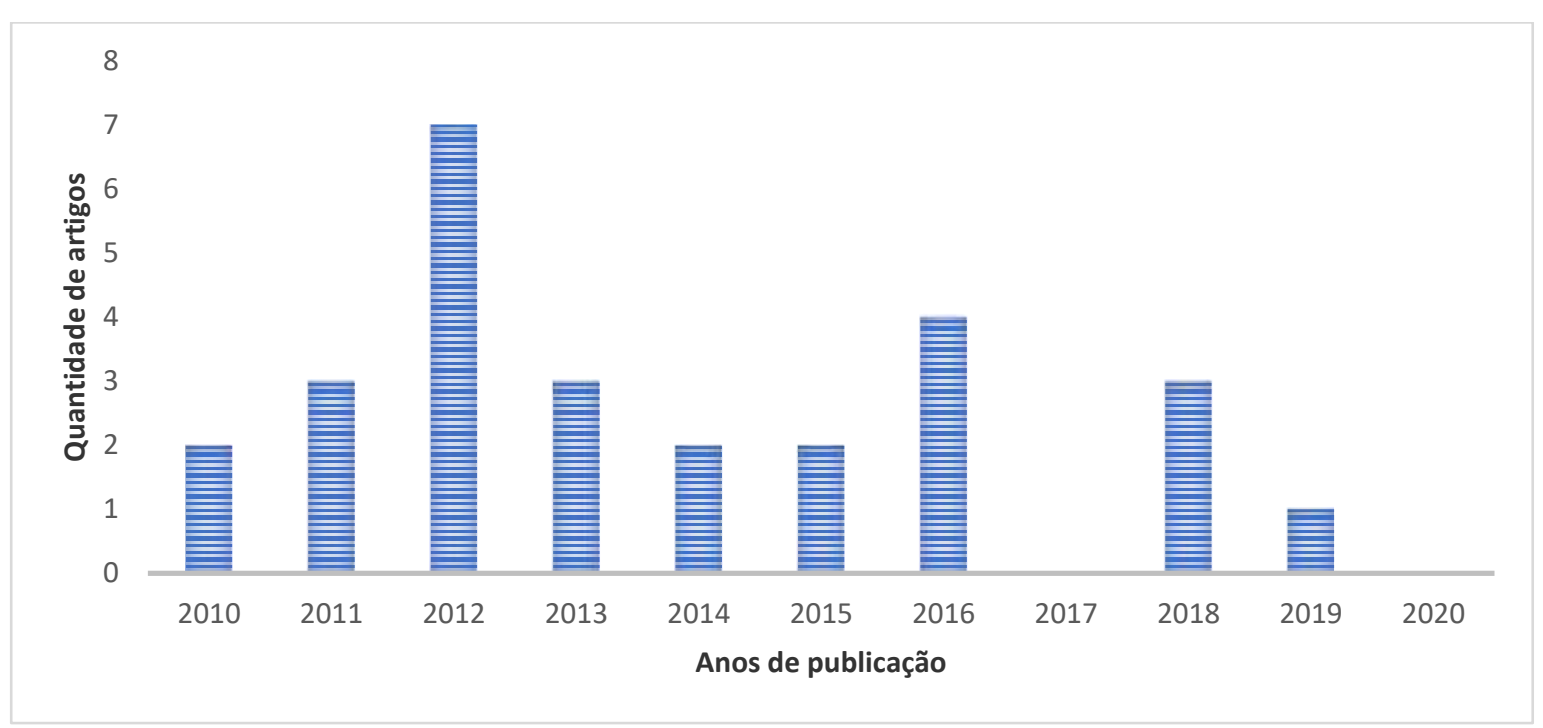

Gráfico 1: Anos de publicação dos artigos analisados - Fonte: dados da pesquisa, 2021

A partir do Gráfico 1, evidencia-se que houve uma concentração de publicações nos anos de 2012 e 2016, totalizando sete e quatro artigos, respectivamente. Ademais, houve uma variação significativa na quantidade de publicações no período escolhido para análise, sendo que, no período entre 2010 a 2012, houve um aumento exponencial; entre 2012 e 2014, constata-se uma queda de mais de cinquenta por cento, número que se manteve em 2015. Em 2016, novamente houve um crescimento, em comparação com o ano anterior, contudo, em 2017, não foi encontrada nenhuma publicação. No ano de 2018, esse número volta a aumentar significativamente, enquanto, em 2019, há uma nova diminuição e, em 2020, não há nenhuma publicação. Portanto, é possível notar uma clara alternância na quantidade de publicações no decorrer dos anos. Ressalta-se ainda que o fato de não haver nenhum artigo condizente com os anos de 2017 e 2020 pode estar associado às bases de dados selecionadas, assim como a seleção das palavras-chave. Ademais, o ano de 2020, com o advento da pandemia, pode ter ficado sem publicações em decorrência do fechamento temporário de algumas instituições e em razão da necessidade de atividades remotas, o que, em alguns casos, exigiu uma nova organização das instituições.

A próxima categoria diz respeito aos tipos de pesquisa, portanto os artigos encontrados foram elencados em quatro categorias principais: estudos empíricos, estudos documentais, estudos conceituais e relatos de experiência, todos tendo como foco o público pertencente aos anos iniciais do ensino fundamental. 


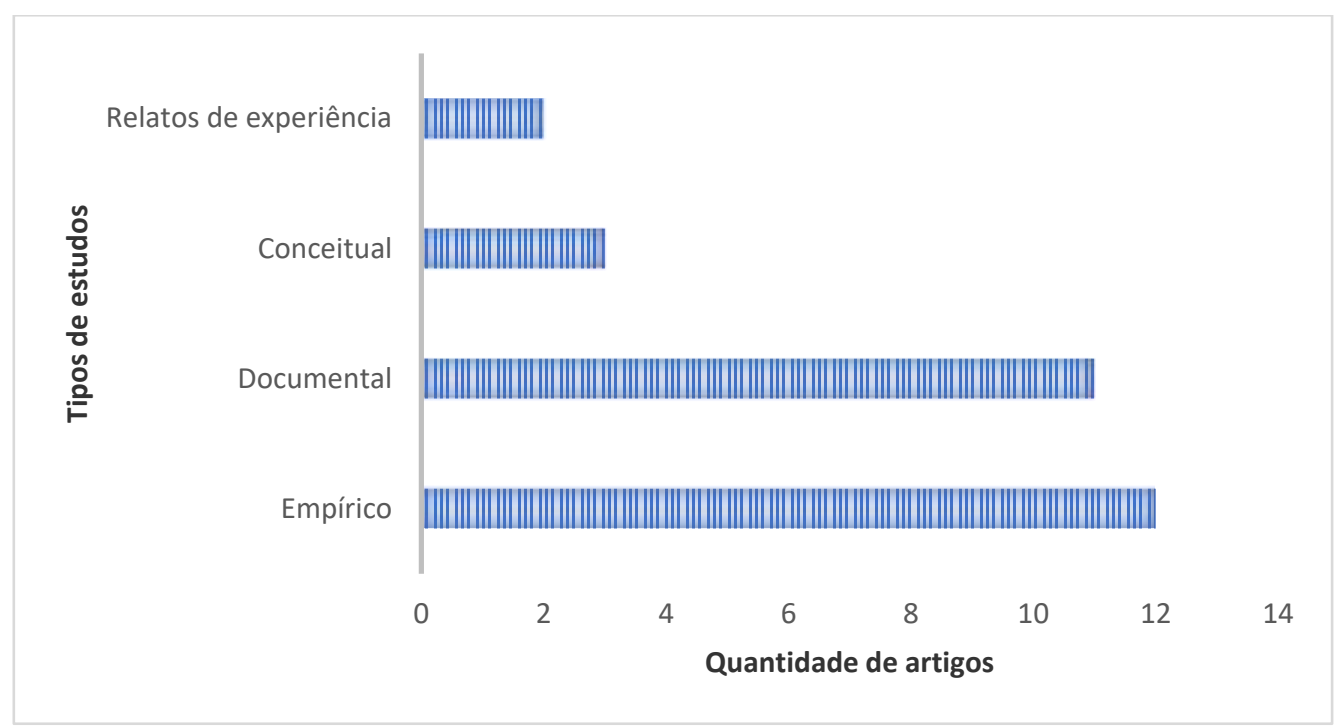

Gráfico 2: Tipos de estudos evidenciados nos artigos - Fonte: dados da pesquisa, 2021

Baseando-se no Gráfico 2, é possível dimensionar que, dentre os quatro principais tipos de estudos evidenciados, doze referem-se a pesquisas empíricas, isto é, fazem uso da aplicação de instrumentos padronizados com estudantes, tanto de escolas públicas, quanto de escolas privadas. Os estudos documentais foram o segundo tipo de pesquisa com uma maior quantidade de publicações, com um total de onze artigos. Nesse caso, as discussões são voltadas, em sua maioria, para análises documentais acerca de resultados de avalições em larga escala. A categoria de estudos conceituais, conta com três trabalhos e é dedicada a ponderações de ordem, exclusivamente, teórico-conceitual e, por fim, a categoria relatos de experiência conta com apenas dois trabalhos e se refere à socialização de experiências práticas em sala de aula.

Dentre os estudos empíricos, no alusivo aos participantes, onze pesquisas envolveram participantes pertencentes do $1^{\circ}$ ao $4^{\circ}$ ano do ensino fundamental. Entretanto, cabe destacar que a maioria das investigações abarcou, especialmente, turmas do $2^{\circ}$ e do $3^{\circ}$ ano. Desse modo, em linhas gerais, os estudos eram voltados para a análise do desempenho da leitura e da escrita desses estudantes. Além disso, apenas dois trabalhos envolveram professores, nesse caso objetivaram investigar aspectos relacionados à avaliação na prática dos docentes, seja estabelecendo articulações com a avaliação externa ou a avaliação no âmbito da sala de aula.

A próxima categoria de análise está relacionada ao constructo abordado nos artigos, sendo eles: leitura, escrita e leitura \& escrita. Tais dados serão expostos no Gráfico 3, de acordo com a porcentagem condizente com cada categoria. 


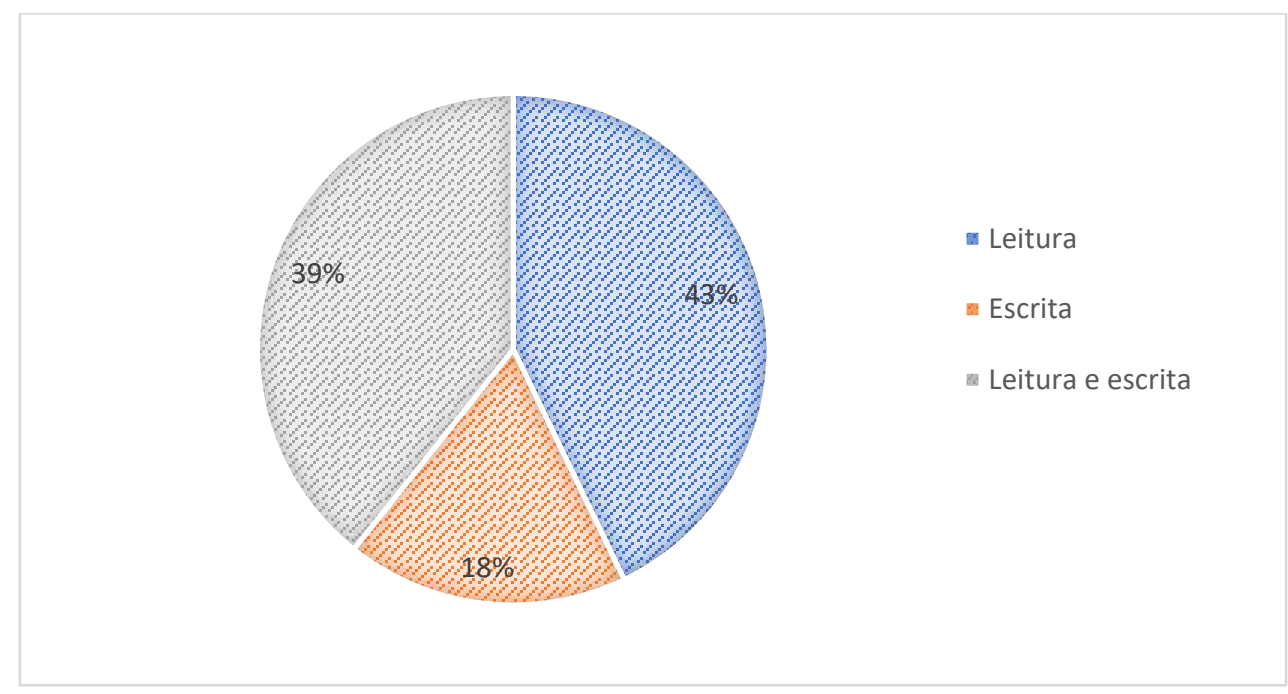

Gráfico 3: Construtos abordados nos artigos - Fonte: dados da pesquisa, 2021

A partir do Gráfico 3, constata-se que 43\% dos artigos analisados eram direcionados à leitura, condizente ao montante de doze trabalhos, enquanto $39 \%$ dos artigos discorrem sobre leitura e escrita de forma conjunta e apenas $18 \%$ dos artigos abordou apenas a escrita. Portanto, por meio do levantamento realizado para o desenvolvimento desta pesquisa, foi possível elucidar que houve uma quantidade pequena de investigações que se dedicava a discorrer exclusivamente sobre escrita. $\mathrm{O}$ foco das discussões foi direcionado essencialmente à leitura, tanto envolvendo pressupostos mais específicos, como mais gerais, ou na articulação entre leitura e escrita. Cabe nos questionarmos o motivo de haver essa prevalência da leitura sobre a escrita.

Em relação à área do conhecimento em que os trabalhos se originam, elas foram consideradas de acordo com a universidade, o grupo ou a linha de pesquisa a que os autores estão vinculados. Por conseguinte, em algumas publicações, essas informações são explícitas; em outras, houve a necessidade de pesquisas adicionais. Os dados serão expostos no Gráfico 4.

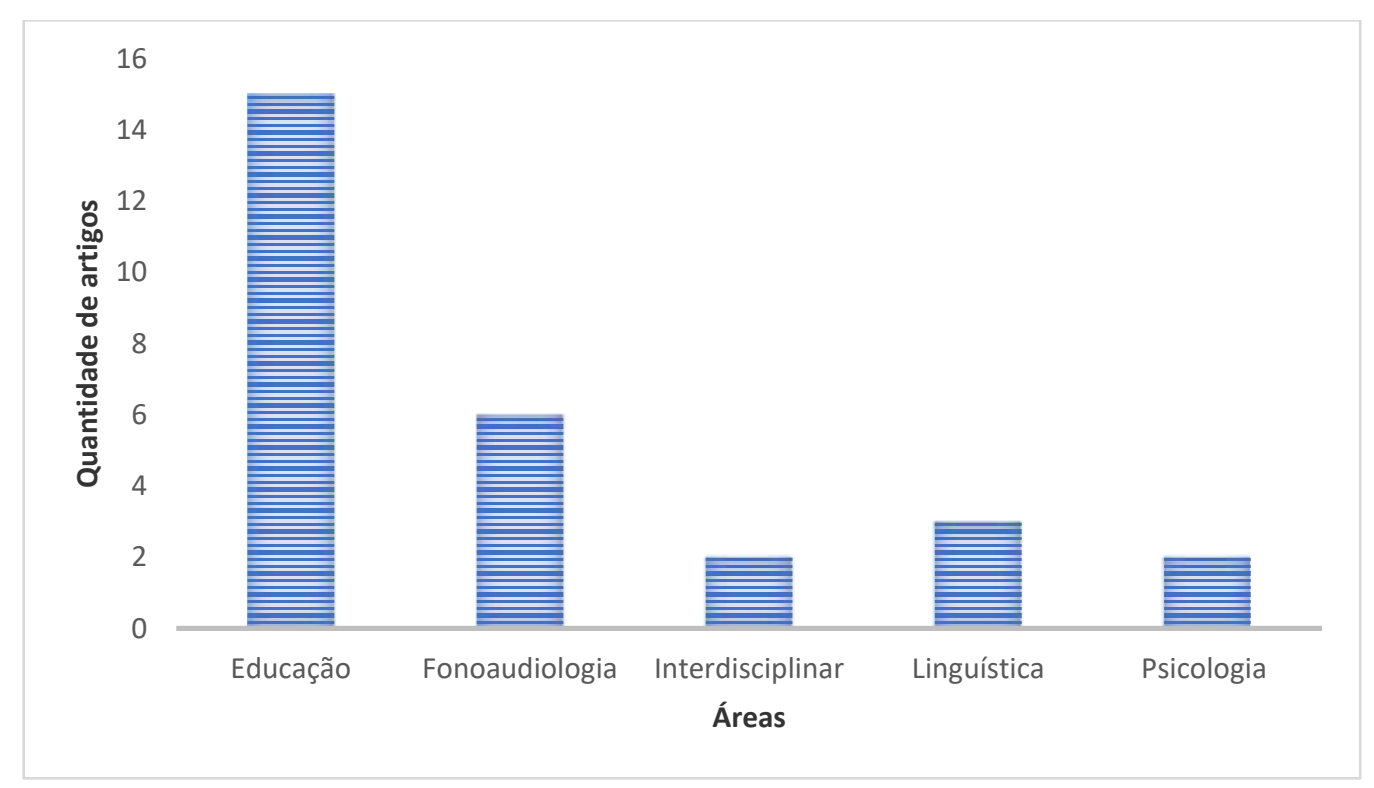

Gráfico 4: Área do conhecimento - Fonte: dados da pesquisa, 2021 
O Gráfico 4 mostra que a maioria das pesquisas são advindas da área da Educação, totalizando quinze artigos, seguida da Fonoaudiologia, com seis artigos, Linguística, com três artigos, e tanto Psicologia quanto a área interdisciplinar com dois artigos, sendo que a categoria interdisciplinar se caracteriza por pesquisas desenvolvidas por pesquisadores de diversas áreas, como, por exemplo, Fonoaudiologia, Psicologia e Linguística. Essa categoria de análise está diretamente articulada com a categoria que irá discorrer sobre a temática dos estudos. De forma preliminar, é pertinente destacar que a maioria dos trabalhos advindos da área da Educação se dedicou a discussões sobre avaliações externas, enquanto os trabalhos de Fonoaudiologia são direcionados ao desempenho dos alunos.

No concernente aos instrumentos utilizados, houve uma variedade considerável de materiais mencionados. Com isso, aqueles mencionados em mais de um artigo, a título de organização do quadro, serão listados apenas uma vez.

\begin{tabular}{|l|l|}
\hline Tipo de pesquisa & \multicolumn{1}{c|}{ Instrumentos } \\
\hline \multirow{5}{*}{ Estudos empíricos } & $\begin{array}{l}\text { Instrumento de avaliação de leitura de palavras e } \\
\text { pseudopalavras isoladas (LDP) }\end{array}$ \\
\cline { 2 - 2 } & Cloze \\
\cline { 2 - 3 } & Teste de Desempenho Escolar \\
\cline { 2 - 3 } & Bateria de identificação dos erros de reversão na leitura e na escrita \\
\cline { 2 - 3 } & Provas para avaliação da compreensão de leitura de palavras e frases \\
\cline { 2 - 3 } & Avaliação de competências iniciais para leitura e escrita (BACLE) \\
\cline { 2 - 3 } & Provas de avaliação dos processos de leitura (PROLEC) \\
\cline { 2 - 3 } & $\begin{array}{l}\text { Adaptação brasileira da bateria de identificação dos erros de } \\
\text { reversão e inversão na escrita }\end{array}$ \\
\cline { 2 - 3 } & Ditado - Observação Ortográfica \\
\cline { 2 - 3 } & Pro-Ortografia \\
\cline { 2 - 3 } & Registros descritivos desenvolvidos pelos professores das turmas \\
\hline \multirow{5}{*}{ Relato de experiência } & Ditado \\
\hline
\end{tabular}

Quadro 1: Instrumentos utilizados e tipo de pesquisa - Fonte: dados da pesquisa, 2021

No Quadro 1, foram elencados todos os instrumentos mencionados nos trabalhos que fizeram parte do corpus de análise atrelado ao tipo de pesquisa, dado que esse aspecto se mostrou como um dado relevante. Assim sendo, nos estudos empíricos, foram mencionados onze instrumentos distintos, todos baseados em princípios paramétricos, com exceção de um, denominado como registros descritivos. Além disso, um artigo utilizou dois instrumentos em conjunto, o Cloze e o Teste de Desempenho Escolar, e apenas o Prolec, de Cuetos, Rodrigues e Ruano (2012) foi mencionado duas vezes, em dois artigos distintos, portanto consideramos 
que não seria viável organizar um gráfico, realizando a quantificação desses resultados. Dentre os instrumentos indicados, quatro são direcionados exclusivamente à avaliação da leitura, três são direcionados à escrita e três envolvem a avaliação da leitura e da escrita.

No concernente aos estudos caracterizados como relatos de experiência, os instrumentos citados foram completamente distintos daqueles das pesquisas empíricas e dizem respeito às sondagens periódicas, realizadas por meio dos ditados baseados em pressupostos de Ferreiro e Teberosky (1999). Nesse contexto, os instrumentos se aproximaram mais do fazer e das práticas dos professores alfabetizadores, que é justamente nosso foco de interesse com esse levantamento bibliográfico. Para além disso, esses instrumentos, assim como os registros descritivos, estão mais relacionados também a aspectos de ordem qualitativa e de acompanhamento no decorrer do ano letivo. Vale ressaltar que os ditados foram reportados nos dois relatos de experiência.

Por fim, a última categoria estabelecida, referente às temáticas abordadas nos artigos selecionados, conta com um total de seis subseções, que serão explicitadas a seguir.

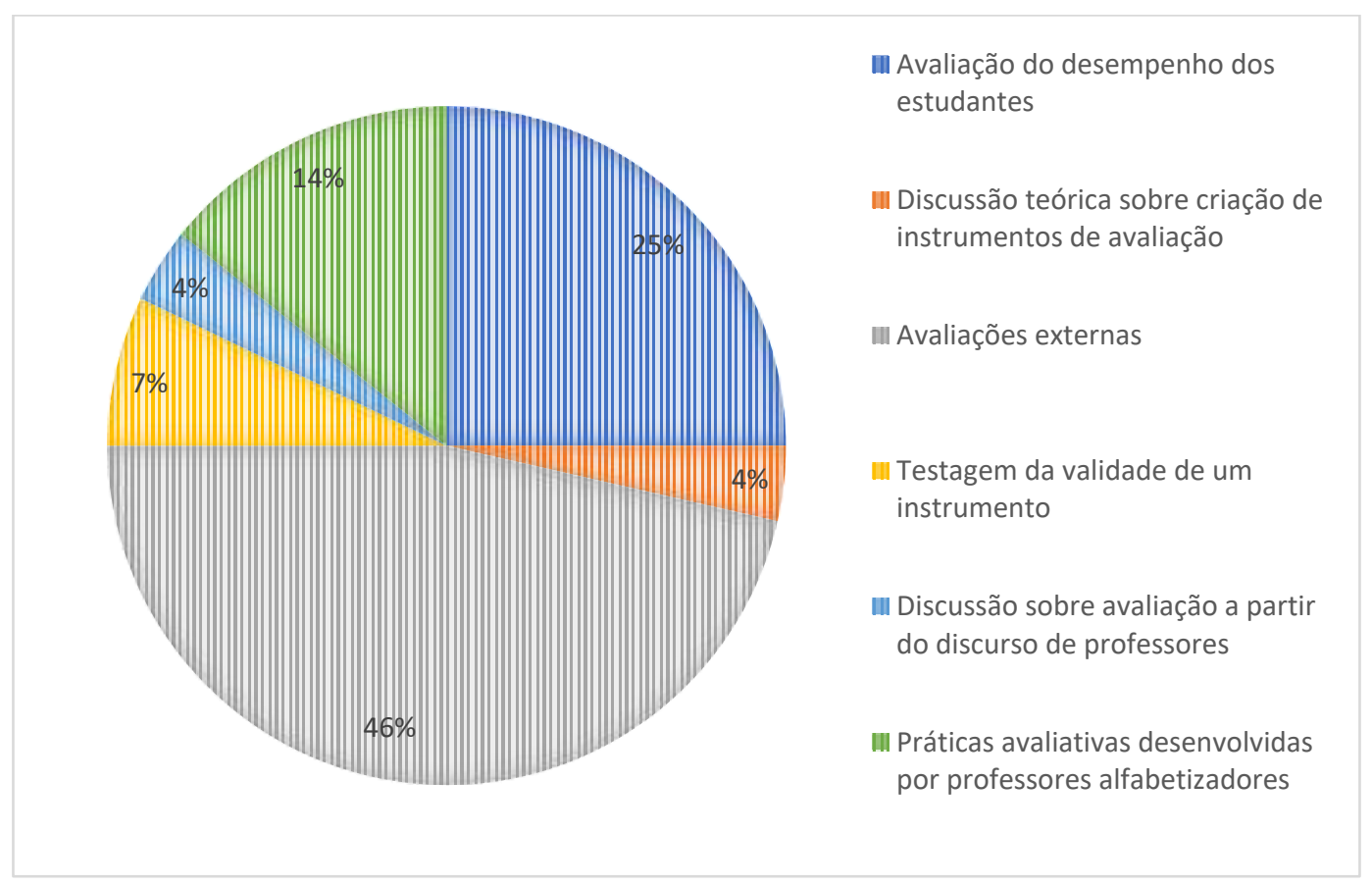

Gráfico 5: Temáticas abordadas nos artigos - Fonte: dados da pesquisa, 2021.

As temáticas presentes nos artigos se mostraram heterogêneas e baseadas em referenciais teóricos que ora se aproximavam, ora se apresentavam complexamente distintos, sendo assim os trabalhos foram agrupados de acordo com eixos centrais, definidos após a leitura integral dos mesmos, sendo eles: avaliação do desempenho dos estudantes, discussão teórica sobre criação de instrumentos de avaliação, avaliações externas, testagem da validade de um instrumento, discussão sobre a avaliação a partir do discurso de professores e práticas avaliativas desenvolvidas por professores alfabetizadores.

As categorias serão mencionadas por ordem de maior incidência de artigos encontrados. Dessa forma, a categoria condizente com $46 \%$ dos artigos diz respeito às avaliações externas, sendo que elas se ramificam em três principais avaliações: a Provinha Brasil, o Programa de Avaliação da Educação Básica do Espírito Santo - Alfabetização (Paebes-Alfa) e a Avaliação Nacional da Alfabetização (ANA). Nesses trabalhos, as avaliações externas são relacionadas às políticas públicas e aos programas governamentais, assim como as habilidades avaliadas nos itens produzidos em diferentes edições, concepções sobre a leitura e escrita subjacentes a essas 
propostas, discussões sobre os resultados de cada uma dessas avaliações e o seu impacto em diferentes contextos. Por conseguinte, há uma pluralidade nas formas de abordagem, e a quantidade de publicações relacionadas à temática sinalizou um número consubstancial, indicando, com isso, que o assunto vem sendo foco de interesse de diversos grupos de pesquisas. Os artigos sobre essa categoria não foram desconsiderados, uma vez que, de forma direta ou indireta, as avaliações externas se entrelaçam com o trabalho desenvolvido em sala de aula, assim como influenciam na construção de currículos e nos planejamentos anuais e semestrais bem como podem vir a condicionar as formas avaliativas em algumas escolas.

A segunda subseção com uma maior quantidade de trabalhos foi intitulada avaliação do desempenho dos estudantes e representa $25 \%$ dos artigos. Nessas investigações, os autores fizeram uso de diferentes instrumentos para avaliar o desempenho em leitura e escrita dos estudantes, estabelecendo comparações entre diferentes anos escolares e a média de acertos de acordo com a seriação, comparações entre escolas públicas e escolas privadas, ou, ainda, associações entre fatores sociais que influenciam na aprendizagem, dentre outros aspectos (CAPELLINI et al., 2012; CÔRREA et al., 2018; FERREIRA et al., 2014; GONÇALVES; CAPELLINI, 2010; OLIVEIRA; CAPELLINI, 2010; OLIVEIRA; GERMANO; CAPELLINI, 2016; SALLES et al., 2013). Nesta subseção, destaca-se a presença de artigos da área da Fonoaudiologia, assim como de autores de um mesmo grupo de pesquisa.

Já a terceira subseção é direcionada aos trabalhos que discorrem sobre práticas avaliativas desenvolvidas por professores alfabetizadores e totalizam 14\% dos artigos. Nos estudos que compõem essa categoria, há relatos de experiências e estudos empíricos, que estabelecem uma articulação direta entre avaliação e alfabetização, evidenciando, com isso, a inegável presença do ditado (FEITAL; MACHADO; ARAUJO, 2015; ROCHA; SANTOS, 2018), como já mencionado ao explicitamos os instrumentos, mas, ao mesmo tempo, há uma diversidade de possibilidades de avaliação, como consequência da heterogeneidade dos grupos atendidos e de inúmeros outros fatores. Nesse caso, surgiram também os registros descritivos (SCHMIDT; SCHAFASCHEK, 2012) e outras formas de avaliação da produção textual infantil (COLLATO, 2016).

Em seguida, na quarta subseção, há estudos dedicados à testagem da validade de um instrumento, representando 7\% do total de artigos. Nesses estudos, há a seleção de grupos de estudantes específicos, com os quais são aplicados determinados instrumentos padronizados, que, nesses casos, consistiram no Cloze e em um instrumento criado pelas próprias autoras, visando avaliar a compreensão leitora, sendo que, a partir da aplicação e da análise dos dados, as autoras buscam evidenciar a eficiência da utilização desses instrumentos para a avaliação dos estudantes (MOTA; SANTOS, 2014; OLIVEIRA; CAPELLINI, 2013).

De modo a finalizar, há duas subseções que apresentaram a mesma quantidade de artigos encontrados, um total de 4\%. Em vista disso, elas serão mencionadas de forma conjunta. São elas: discussão sobre avaliação a partir do discurso de professores e discussão teórica sobre a criação de instrumentos de avaliação. No alusivo à primeira subseção, as autoras estabelecem articulações entre as práticas de professores alfabetizadores e o impacto de um programa de avaliação externa do Estado de Minas Gerais (CARVALHO; MACEDO, 2011) e, por fim, em relação à última subseção, há considerações voltadas para questões metodológicas e conceituais que devem ser consideradas na criação de instrumentos de avaliação de habilidades metalinguísticas (MOTA, 2012).

Em suma, diante desta revisão sistemática da literatura preliminar, é possível realizar algumas indicações e ponderações. A primeira está relacionada a uma clara dicotomia na avaliação desenvolvida no âmbito das pesquisas científicas e na avaliação desenvolvida nas salas de aula da educação básica, retratadas nos artigos analisados, embora ambas envolvam o mesmo público. As primeiras são embasadas em conceitos que visam à mensuração e princípios psicométricos, portanto aspectos de ordem quantitativa. Já as segundas estão articuladas às práticas dos 
professores alfabetizadores, que se embasam também em aspectos teóricos e conceituais, contudo sob uma abordagem qualitativa e processual. Aliado a isso, é possível dimensionar que a área em que a pesquisa se origina, consequentemente, influencia na concepção de avaliação. Não obstante, era justamente esse segundo grupo de estudos que nos interessava naquele momento, contudo, na revisão realizada, houve o contato com apenas quatro trabalhos, sendo dois relatos de experiências, um estudo documental e um estudo empírico. Assim, considera-se, portanto, a existência de um evidente distanciamento entre estudos que investigam a avaliação da leitura e da escrita nos anos iniciais do ensino fundamental no âmbito da sala de aula e a avaliação no âmbito de pesquisas científicas que são aplicadas com determinados grupos de estudantes.

O segundo aspecto está articulado ao reduzido número de trabalhos que se dedicam à discussão acerca dos instrumentos e das formas de avaliação com foco, exclusivamente, no período de alfabetização. A maioria deles se atem às avaliações externas e às avaliações do desempenho dos estudantes a partir de instrumentos padronizados. Consideramos que investigar as práticas avaliativas dos professores alfabetizadores, atreladas a questões de planejamento e de ensino-aprendizagem, pode fornecer subsídios enriquecedores para pensarmos em uma avaliação da alfabetização que seja contextualizada, processual e formativa.

\section{Considerações finais}

Este trabalho teve como objetivo compreender, por intermédio de uma revisão sistemática da literatura nacional, as formas de avaliação da leitura e da escrita, assim como quais instrumentos são utilizados no contexto da alfabetização. A despeito dos principais aspectos evidenciados a partir da análise dos artigos, constatou-se uma concentração de publicações dos estudos entre o período de 2012 a 2016. Embora haja evidentes oscilações, há ainda anos em que não houve nenhuma publicação encontrada, como em 2017 e 2020.

No alusivo aos tipos de estudos, a maioria dos artigos refere-se, essencialmente, a estudos empíricos, nos quais houve a aplicação de instrumentos padronizados junto aos estudantes, e a estudos documentais, direcionados, em grande medida, às avaliações externas. Sobre o construto abordado, a escrita foi a categoria que apresentou a menor quantidade de investigações, totalizando apenas cinco artigos. Isso nos direciona para a necessidade de investigações que abordem a escrita de forma individual e abarquem as suas especificidades ao pensar na avaliação atrelada ao contexto do processo de alfabetização.

No concernente às áreas do conhecimento, a maioria dos artigos é oriunda da Educação, seguida da Fonoaudiologia, e está diretamente articulada às temáticas, que se subdividem em seis subseções com características distintas entre si. As subseções que apresentaram uma maior quantidade de estudos estão vinculadas às temáticas das avaliações externas, avaliação do desempenho de estudantes e práticas avaliativas desenvolvidas por professores alfabetizadores, sendo que a primeira e terceira subseção foram investigações majoritariamente da área educacional e fonoaudiológica.

Por fim, dos doze instrumentos avaliativos mencionados, onze pertencem a estudos empíricos e um, o ditado, a estudos caracterizados como relatos de experiência. Portanto, há uma clara polarização entre os instrumentos e as formas de avaliação existentes nos artigos que fizeram parte do corpus de análise. De um lado, há avaliações que se aproximam de princípios paramétricos e de mensuração, abordando aspectos quantitativos, enquanto, de outro, há avaliações processuais e descritivas, com ênfase em pressupostos qualitativos. Todavia, os primeiros se sobressaem aos segundos.

Assim, essa revisão da literatura nos fornece indícios quanto à importância da parceria entre universidades e escolas de educação básica, de forma que haja uma interlocução desses conhecimentos, que são produzidos em diferentes âmbitos, aliada à necessidade do desenvolvimento 
de investigações das práticas avaliativas de professores alfabetizadores em seu contexto de trabalho, buscando compreender como essas práticas influenciam no planejamento docente, e como a avaliação pode, de fato, trazer contribuições ao processo de ensino-aprendizagem.

\section{Referências}

CAPELLINI et al. Desempenho ortográfico de escolares do $2^{\circ}$ ao $5^{\circ}$ ano do ensino fundamental. Rev. CEFAC, Campinas, v. 2, n. 2, p. 254-275, mar./abr. 2012.

CARMINATTI, Simone Soares Haas; BORGES, Marta Kaschny. Perspectivas da avaliação da aprendizagem na contemporaneidade. Est. Aval. Educ., v. 23, n. 52, p. 160-178, 2012.

CARVALHO, Gisele Francisca da Silva; MACEDO, Maria do Socorro Alencar Nunes. Avaliação oficial: o que dizem os professores sobre o impacto na prática docente. Educação e Pesquisa, São Paulo, v. 37, n. 3, p. 549-564, set./dez. 2011.

COLLATO, Luísa Jacques. Avaliação do texto infantil: descobertas e possibilidades. Revista Even. Pedagóg., v. 7, n. 2, p. 865-891, jun./jul. 2016.

CÔRREA et al. Competências iniciais para o processo de alfabetização. CoDAS, São Paulo, v. 30, n. 1, p. 1-7, 2018.

CUETOS, Fernando; RODRIGUES, Bianca; RUANO, Elvíra. PROLEC: provas de avaliação dos processos de leitura. 2. ed. São Paulo: Casa do Psicólogo, 2012.

FEITAL, Andreia Alvim Bellotti; MACHADO, Miriam Raquel Piazzi; ARAUJO, Rita de Cássia Barros de Freitas. Práticas avaliativas: relato de experiência no $1^{\circ}$ ano do Ensino Fundamental do Colégio de Aplicação João XXIII. Educ. Foco, Juiz de Fora, ed. especial, p. 81-95, fev. 2015.

FERREIRA et al. A aprendizagem da escrita e a escolaridade materna. Rev. CEFAC, Campinas, v. 16, n. 2, p. 446-456, mar./abr. 2014.

FERREIRO, Emilia; TEBEROSKY, Ana. Psicogênese da língua escrita. Porto Alegre: Artmed, 1999.

GONÇALVES, Beatriz Aparecida Gimenez; CAPELLINI, Simone Aparecida. Desempenho de escolares de $1^{a}$ série na bateria de identificação de erros de reversão e inversão na escrita: estudo preliminar. Rev. CEFAC, Campinas, v. 12, n. 6, p. 998-1008, nov./dez. 2010.

LIMA, Maria de Fátima Moura de. A avaliação de conhecimentos das crianças relacionados à leitura e à escrita práticas de professores do $1^{o}$ ano do Ensino Fundamental. 2015. 165f. Dissertação (Mestrado em Educação) - Universidade Federal de Pernambuco, Recife, 2015.

MORAIS, Artur Gomes de; LEAL, Telma Ferraz. Alfabetização e sua avaliação no Brasil: um balanço crítico a partir de diferentes pesquisas. Em Aberto, Brasília, v. 33, n. 108, p. 1924, maio/ago. 2020. 
MORAIS, Artur Gomes de. Políticas de avaliação: discutindo a Provinha Brasil. Rev. Bras. Educ., Rio de Janeiro, v. 17, n. 51, p. 551-742, set./ dez. 2012.

MOTA, Márcia Maria Peruzzi Elia da. Considerações metodológicas e conceituais sobre a construção de instrumentos de avaliação das habilidades metalinguísticas. Aval. psicol., Itatiba, v. 11, n. 1, p. 77-82, abr. 2012.

MOTA, Márcia Maria Peruzzi Elia da; SANTOS, Acácia Aparecida Angeli dos. O Cloze como instrumento de avaliação de leitura nas séries iniciais. Revista Quadrimestral da Associação Brasileira de Psicologia Escolar e Educacional, São Paulo, v. 18, n. 1, p. 135-142, jan./abr. 2014.

OLIVEIRA, Adriana Marques de; CAPELLINI, Simone Aparecida. Compreensão leitora de palavras e frases: elaboração de procedimentos avaliativos. Psicologia em Estudo, Maringá, v. 18, n. 2, p. 293-301, abr./jun. 2013.

OLIVEIRA, Adriana Marques de; CAPELLINI, Simone Aparecida. Desempenho de escolares na adaptação brasileira da avaliação dos processos de leitura. Pró-Fono: Revista de Atualização Científica, Barueri, v. 22, n. 4, p. 555-560, out./ dez. 2010.

OLIVEIRA, Adriana Marques de; GERMANO, Giseli Donadon; CAPELLINI Simone Aparecida. Desempenho de escolares em provas de processo de identificação de letras e do processo léxico. Rev. CEFAC, v. 18, n. 5, p. 1121-1132, set./out. 2016.

PERRENOUD, Philippe. Avaliação da excelência à regulação das aprendizagens: entre duas lógicas. Porto Alegre: Artmed, 1999.

ROCHA, Patrícia Rodrigues; SANTOS, Alessandra de Souza. A importância da sondagem da escrita como instrumento de avaliação no período da alfabetização. Revista Prática Docente, Mato Grosso, v. 3, n. 2, p. 453-460, jul./dez. 2018.

SALLES, Jerusa Fumagalli et al. Normas de desempenho em tarefas de leitura de palavras/ pseudopalavras isoladas (LPI) para crianças de $1^{\circ}$ ano a $7^{\circ}$ ano. Estudos e Pesquisas em Psicologia, v. 13, n. 2, p. 397-419, 2013.

SCHMIDT, Leonete Luzia; SCHAFASCHEK, Rosicler. A avaliação em classes de alfabetização: registros descritivos possibilitam superação da avaliação classificatória e excludente? Roteiro, Joaçaba, v. 37, n. 2, p. 228-242, jul./dez. 2012.

SOARES, Magda. Alfabetização: a questão dos métodos. São Paulo: Editora Contexto, 2018.

SPERRHAKE, Renata; PICCOLI, Luciana. Instrumentos para avaliação formativa da alfabetização: princípios conceituais e metodológicos. Em Aberto, Brasília, v. 33, n. 108, p. 47-67, maio/ago. 2020. 


\section{Sobre as autoras}

Aline Gasparini Zacharias-Carolino. Doutoranda em Educação pela Universidade Estadual Paulista - UNESP, integrante do Grupo de Estudos e Pesquisas em Representações, Aprendizagem, Leitura e Escrita - GEPRALE e professora da Educação Básica.

E-mail: aline.gasparini@unesp.br.

Andréia Osti. Professora do Departamento de Educação da Universidade Estadual Paulista (UNESP) credenciada junto ao Programa de Pós-Graduação em Educação da UNESP de Rio Claro. Doutora em Educação (2010) pela Faculdade de Educação da Universidade Estadual de Campinas (UNICAMP), onde também concluiu os cursos de Mestrado em Educação (2004). Coordena o Grupo de Estudos e Pesquisas em Representações, Aprendizagem, Leitura e Escrita - GEPRALE, credenciado junto ao CNPq desde 2017.

E-mail: andreia.osti@unesp.br. 